\title{
Study of in Vitro Interaction of Sildenafil Citrate with Bovine Serum Albumin by Fluorescence Spectroscopy
}

\author{
Md. Abdus Salam1, Md. Rokonujjaman1, Asma Rahman², Ummay Nasrin Sultana², \\ Md. Zakir Sultan ${ }^{2 *}$ \\ ${ }^{1}$ Department of Chemistry, University of Dhaka, Dhaka, Bangladesh \\ ${ }^{2}$ Centre for Advanced Research in Sciences (CARS), University of Dhaka, Dhaka, Bangladesh \\ Email: ${ }^{*}$ zakir.sultan@du.ac.bd
}

Received 20 December 2014; accepted 10 February 2015; published 12 February 2015

Copyright @ 2015 by authors and Scientific Research Publishing Inc.

This work is licensed under the Creative Commons Attribution International License (CC BY). http://creativecommons.org/licenses/by/4.0/

c) (i) Open Access

\begin{abstract}
In vitro interaction of sildenafil citrate (SC) with bovine serum albumin (BSA) was investigated at two excitation wavelengths of BSA $(280 \mathrm{~nm}$ and $293 \mathrm{~nm})$ at two different temperatures $(298 \mathrm{~K}$ and $308 \mathrm{~K}$ ) by fluorescence emission spectroscopy. The study showed that quenching of BSA fluorescence by sildenafil citrate was the result of formation BSA-SC complex with probable involvement of both tryptophan and tyrosine residues of BSA. Fluorescence quenching constant was determined from Stern-Volmer equation, and both static quenching and dynamic quenching were showed for BSA by SC at the conditions. Van't Hoff equation was used to measure the thermodynamic parameters $\Delta G, \Delta H$, and $\Delta S$ at the temperatures which indicated that the hydrogen bond and the hydrophobic forces played major roles for BSA-SC complexation. The binding number (n) was found to be $\approx 1$ indicating that one mole BSA bound with one mole SC. The binding affinity of SC to BSA was calculated at different temperatures. The binding constant was decreased with increasing temperatures indicating that stability of BSA-SC complex decreased with increasing temperatures.
\end{abstract}

\section{Keywords}

Sildenafil Citrate, Bovine Serum Albumin, Quenching, Fluorescence Spectroscopy

\section{Introduction}

Sildenafil citrate (Figure 1) is a drug used to treat erectile dysfunction and pulmonary arterial hypertension (PAH)

*Corresponding author.

How to cite this paper: Salam, M.A., Rokonujjaman, M., Rahman, A., Sultana, U.N. and Zakir Sultan, M. (2015) Study of in Vitro Interaction of Sildenafil Citrate with Bovine Serum Albumin by Fluorescence Spectroscopy. Pharmacology \& Pharmacy, 6, 94-101. http://dx.doi.org/10.4236/pp.2015.62012 


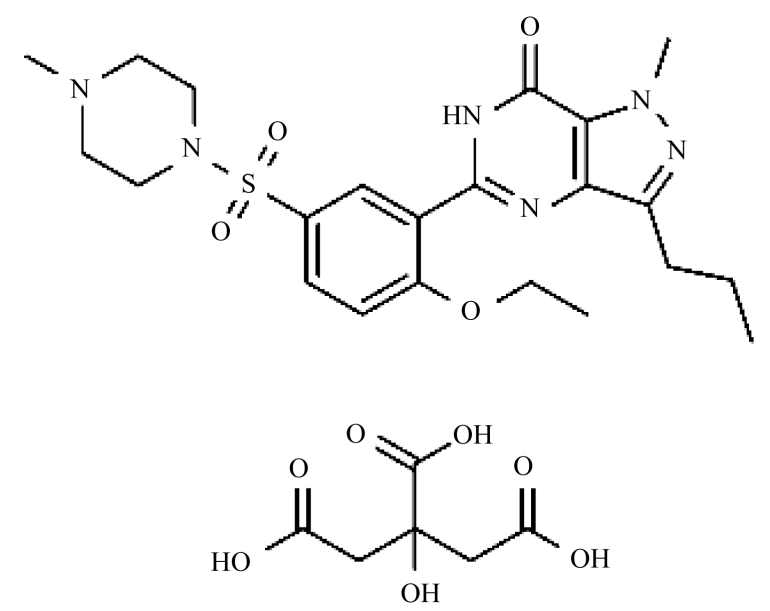

Figure 1. Chemical structure of sildenafil citrate (SC).

[1]. It acts by inhibiting cGMP-specific phosphodiesterase type 5 (PDE5), an enzyme that promotes degradation of cGMP, which regulates blood flow in the smooth muscle. Sildenafil has no direct relaxant effect on isolated human corpus cavernosum, but enhances the effect of nitric oxide (NO) by inhibiting phosphodiesterase type 5 (PDE5), which is responsible for degradation of cGMP in the corpus cavernosum.

Serum albumin is the most abundant soluble protein in human blood plasma and they are serving as deport protein and binding of numerous ligands, such as fatty acids, drugs, and metal ions, in the bloodstream to their target organs [2] [3]. Therefore, serum albumin is considered as a model to study the drug-protein interaction in vitro [4]. Bovine serum albumin (BSA) is an extensively studied ideal protein model of albumin group since it displays $80 \%$ homology with human serum albumin (HSA) [5]. BSA is an ideal protein of a single polypeptide chain of 583 amino acid residues and three structurally homologous domains (I-III) which are divided into nine loops (L1-L9) by 17 disulfide bonds, and each domain is further divided into two sub-domains (A and B) [6]. It is a convenient protein for intrinsic fluorescence measurement due to the presence of two intrinsic tryptophan (Trp) residues which is highly sensitive to its local environment, and can be used to observe changes in the fluorescence emission spectra due to protein conformational changes, binding to substrates, and denaturation [7]. There are also numerous tyrosine residues of BSA depending on the excitation wavelength selected which have minor contribution for intrinsic fluorescence. Trp-212, located within the hydrophobic binding pocket of subdomain IIA (site-I), and Trp-134, located on the surface of sub-domain IB (site-II) [8]-[10]. The binding sites of BSA for endogenous and exogenous ligands may be in these domains, and some ligands specifically bind to the different domains of serum albumin [11]. However, BSA plays an important role in binding of numerous drugs in the bloodstream to their target organs for understanding the pharmacokinetics and pharmacodynamics properties of drug candidates.

Drugs bound at molecular level to proteins are acted as carriers which lead to the interpretation of the metabolism, distribution, free concentration, efficacy and transporting process of drugs [12]. Moreover, investigation of drug-protein interaction provides the information of structural features determining the therapeutic effect of drugs helping to understand the drug toxicity and playing a key role in the researching pharmacology, pharmacodynamics and biochemistry. Therefore drug-protein binding has become an important research field in life sciences, chemistry and clinical medicine [13] [14].

There are some popular techniques which have been used to investigate the interaction between drugs and BSA. Fluorescence spectroscopy is one of the powerful techniques to study molecular interactions which change local environment of fluorophore and help to predict the binding phenomenon of drugs to BSA [15]. However, the in vitro mechanism of interactions of SC with BSA in presence has not been explored. So it is significant to study the interaction between SC and BSA by fluorescence spectroscopy.

In the present study, in vitro interaction of SC with BSA has been studied by fluorescence emission spectroscopy at two excitation wavelengths of BSA $(280 \mathrm{~nm}$ and $293 \mathrm{~nm})$ at two different temperatures. For this study, participating residues, quenching constant, thermodynamic parameters and forces, binding constant and binding number at mentioned conditions were measured. 


\section{Materials and Method}

\subsection{Reagent and Materials}

All chemicals and reagents were of analytical grade and doubly distilled water was used throughout the study. BSA (fatty acid free, fraction $\mathrm{V}, 96 \%$ - 98\%), sodium dihydrogen phosphate $\left(\mathrm{NaH}_{2} \mathrm{PO}_{4}\right)$, potassium dihydrogen phosphate $\left(\mathrm{KH}_{2} \mathrm{PO}_{4}\right)$ were purchased from Sigma Chemical Co., USA., and sildenafil citrate (99.4\%) was kind gift from the ACI Ltd., Bangladesh.

\subsection{Apparatus}

All fluorescence spectra were recorded on fluorescence spectrophotometer (Model: F-7000, Hitachi, Japan) equipped with $1.0 \mathrm{~cm}$ quartz cell. For different temperatures a thermostat bath (Unitronic Orbital, P-Spectra, Spain) was used.

\subsection{Sample Preparation}

Five $\mathrm{mL}$ of previously prepared $20 \times 10^{-6} \mathrm{~mol} \cdot \mathrm{L}^{-1} \mathrm{BSA}$ in phosphate buffer of $\mathrm{pH} 7.4$ was taken in each of the eight test tubes. Sildenafil citrate was added in different volumes to seven out of eight test tubes to have the following concentrations: $\left(20,40,80,120,160,240\right.$ and 320) $\times 10^{-6} \mathrm{~mol} \cdot \mathrm{L}^{-1}$, respectively. The ratio of SC and BSA ([SC]/[BSA]) in BSA-SC system of seven test tubes were 1:1, 2:1, 4:1, 6:1, 8:1, 12:1 and 16:1, respectively. The mixture solutions of BSA and SC must be hatched at least 5 min before the spectroscopic measurements.

\subsection{Spectroscopic Measurement}

The fluorescence emission spectra for BSA-SC system were recorded at the two excitation wavelengths of BSA $(280 \mathrm{~nm}$ and $293 \mathrm{~nm}$ ) at two different temperatures (298 K and $308 \mathrm{~K}$ ). The widths of both entrance and exit slit were set to $5 \mathrm{~nm}$. These emission spectra were recorded for three times for each treatment in the range of 320 $460 \mathrm{~nm}$ for BSA at same experimental conditions since there were no emission spectra of SC in this range.

\section{Results and Discussion}

\subsection{The Interaction of SC with BSA}

When BSA is excited by appropriate wavelength of light, all of its fluorophores (tryptophan, tyrosine and phenylalanine) can emit fluorescence. When $280 \mathrm{~nm}$ excitation wavelength is used, fluorescence of albumin comes from both tryptophan and tyrosine residues, whereas $293 \mathrm{~nm}$ wavelength only excites tryptophan residues [16]. It was compared the fluorescence of BSA excited at $280 \mathrm{~nm}$ and $293 \mathrm{~nm}$ in the presence of SC that would be determined the interactions residues of BSA with SC. The plots $\mathrm{F} / \mathrm{F}_{0}$ against [SC]/[BSA] at excitation wavelengths $280 \mathrm{~nm}$ and $293 \mathrm{~nm}$ were compared at $298 \mathrm{~K}$, respectively. Here, $\mathrm{F}_{\mathrm{o}}$ is the fluorescence intensity of BSA, $\mathrm{F}$ is the fluorescence intensity of BSA in presence of SC.

Figure 2 indicates that the fluorescence of BSA excited at $280 \mathrm{~nm}$ obviously differed from that excited at 293 $\mathrm{nm}$ in the presence of SC. This difference between quenching of serum albumin fluorescence showed that the both tyrosine and tryptophan residues participated in the molecular interactions between BSA and SC.

\subsection{Effect of SC on the Fluorescence Emission Spectra of BSA}

In order to determine the effect of SC with BSA, the fluorescence emission spectra were measured at two excitation wavelengths of BSA ( $280 \mathrm{~nm}$ and $293 \mathrm{~nm}$ ) at two different temperatures (298 K and $308 \mathrm{~K}$ ).

Figure 3 shows the fluorescence of BSA gradually decreased with the increasing concentration of SC, indicating that there was a strong interaction and energy transfer between SC and BSA at the both excitation wavelengths of BSA ( $\lambda \mathrm{Ex}_{\max }$ of BSA $=280 \mathrm{~nm}$ and $293 \mathrm{~nm}$ ) at two different temperatures ( $298 \mathrm{~K}$ and $\left.308 \mathrm{~K}\right)$. As a result, there were quenching of intrinsic fluorescence of BSA but no significant shift of the emission maximum wavelength was observed.

\subsection{Fluorescence Quenching Analysis}

Quenching refers to any process which decreases the fluorescence intensity of a given substance (fluorophore) 


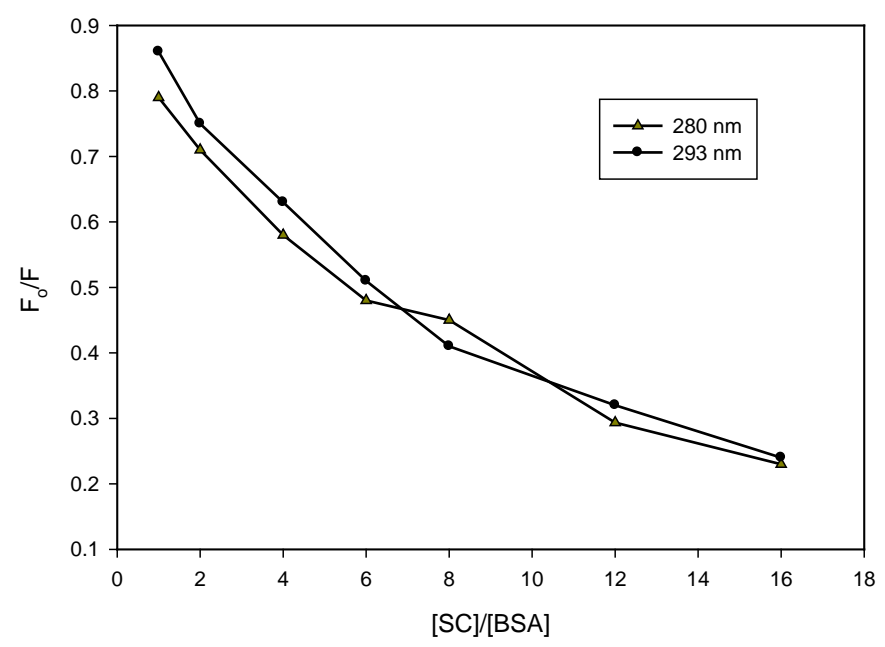

Figure 2. Fluorescence titration curve of BSA in presence of SC at the excitation wavelength of $280 \mathrm{~nm}$ and $293 \mathrm{~nm}$ at $298 \mathrm{~K}$.

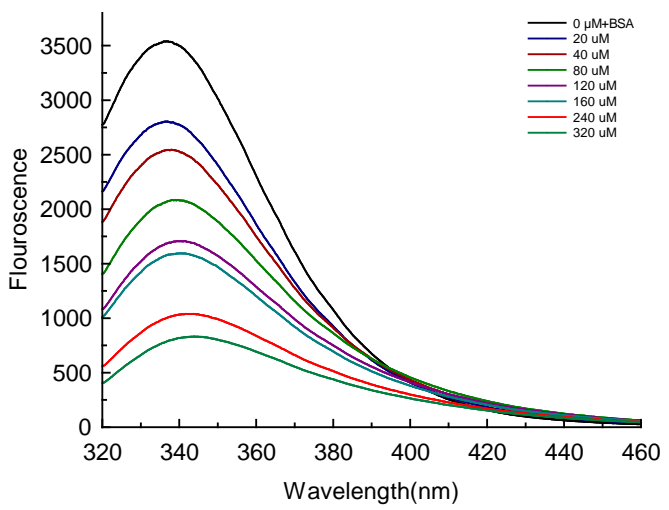

(a)

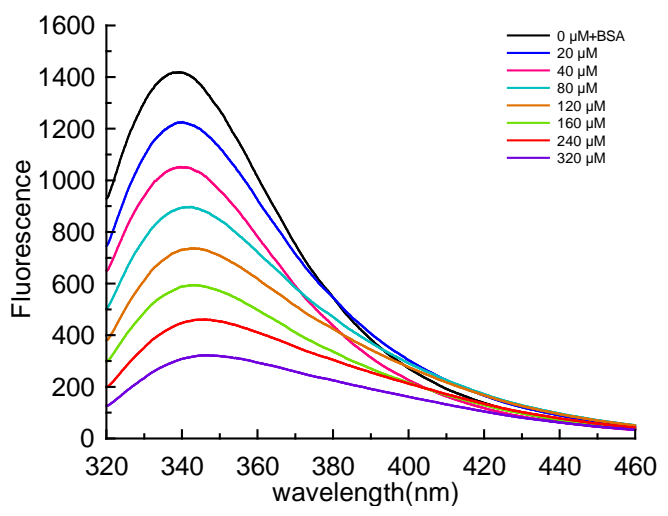

(c)

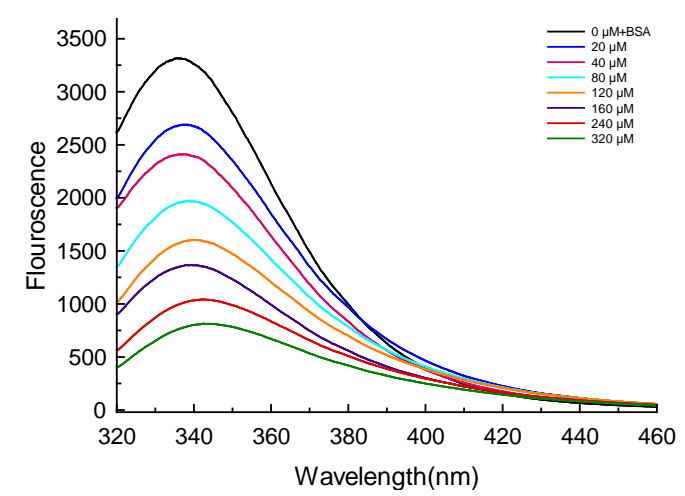

(b)

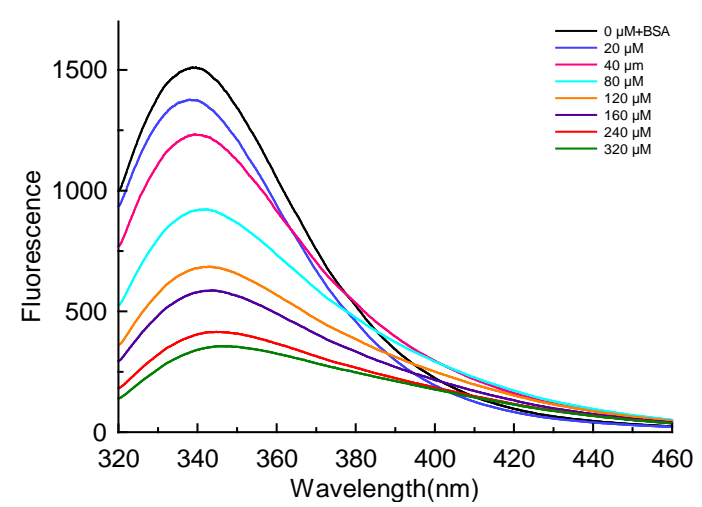

(d)

Figure 3. Fluorescence emission spectra of BSA-SC system at the excitation of (a) $280 \mathrm{~nm}$ at $298 \mathrm{~K}$; (b) $280 \mathrm{~nm}$ at $308 \mathrm{~K}$; (c) $293 \mathrm{~nm}$ at $298 \mathrm{~K}$; (d) $293 \mathrm{~nm}$ at $308 \mathrm{~K}$.

induced by a variety of molecular interactions with quencher molecule [17]. A variety of processes can result in quenching, such as excited state reactions, energy transfer, complex-formation and collisional quenching. Formation of complex between quencher and the fluorophore refers to static quenching. On the other hand, collision of the quencher and fluorophore during the excitation refers to dynamic quenching [18]. The fluorescence quenching data are usually analyzed by Stern-Volmer equation [7]. 


$$
\mathrm{F}_{\mathrm{o}} / \mathrm{F}=1+\mathrm{Ksv}[\mathrm{Q}]
$$

where, $F_{0}$ and $F$ are the fluorescence intensities in the absence and presence of quencher, [Q] is the quencher concentration and Ksv is the Stern-Volmer quenching constant which indicates the strength of interaction between albumin protein and quencher molecule. Hence, this equation was applied to determine Ksv by linear regression of a plot of $\mathrm{F}_{\mathrm{o}} / \mathrm{F}$ against [Q]. The static quenching distinguished from dynamic quenching by their differing dependence of temperature [7]. Dynamic quenching depends upon diffusion and higher temperatures result in larger diffusion coefficients. As a result, the Stern-Volmer quenching constants (Ksv) were expected to increase with increasing temperature. In contrast, increased temperature is likely to result in decreasing stability of complexes, and thus lower value of static quenching constants [19].

The pattern of quenching of BSA fluorescence by SC was determined by measuring the value of SternVolmer quenching constant (Ksv) at the excitation wavelength of BSA (280 nm and $293 \mathrm{~nm})$ at two different temperatures ( $298 \mathrm{~K}$ and $308 \mathrm{~K}$ ). Ksv was calculated from the slope of the plot of $\mathrm{F} / \mathrm{F}_{\mathrm{o}}$ versus concentration of SC based on the fluorescence data (Figure 4) at the conditions.

Figure 4 displays the Stern-Volmer plots of the quenching of BSA fluorescence by SC at two excitation wavelength of BSA (280 nm and $293 \mathrm{~nm}$ ) at two different temperatures (298 K and $308 \mathrm{~K}$ ). The plots showed that within the experimental concentrations, the results were good agreement with the Stern-Volmer equation. The plots were linear and Stern-Volmer quenching constants were obtained from the slopes at two different temperatures; these are mentioned in Table 1. The Stern-Volmer quenching constant decreased with increasing temperature for static quenching while for dynamic quenching the reverse effect was observed [20]. It was seen from the Table 1 that the Ksv decreased by increasing temperature at $280 \mathrm{~nm}$ but increased by increasing temperature at $293 \mathrm{~nm}$. So it was observed that both dynamic and static quenching were present of BSA by SC at two different temperatures.

\subsection{Thermodynamic Parameters and Nature of Binding Forces}

There are many interaction forces (e.g. hydrophobic force, electrostatic interactions, Vander Waals interactions,

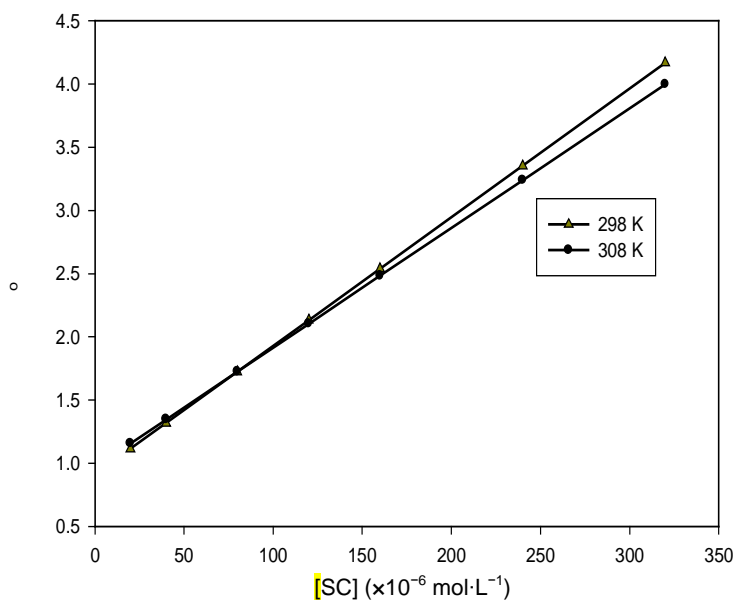

(a)

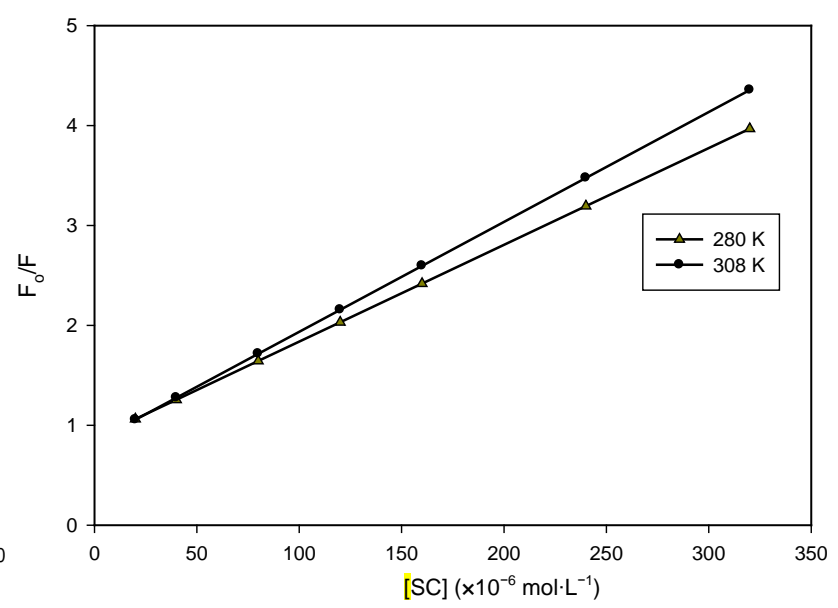

(b)

Figure 4. The Stern-Volmer plots for BSA-SC system at the excitation wavelength of BSA (a) $280 \mathrm{~nm}$ and (b) $293 \mathrm{~nm}$ at two different temperatures (298 K and $308 \mathrm{~K}$ ).

Table 1. The Stern-Volmer quenching constant (Ksv) for BSA-SC system at $280 \mathrm{~nm}$ and 293 $\mathrm{nm}$ at two different temperatures (298 K and $308 \mathrm{~K}$ ).

\begin{tabular}{ccc}
$\mathbf{T}(\mathbf{K})$ & $\mathbf{K s v}\left(\times \mathbf{1 0}^{\mathbf{3}} \mathbf{L} \cdot \mathbf{m o l}^{-\mathbf{1}}\right)$ at $\mathbf{2 8 0} \mathbf{~ n m}$ & $\mathbf{K s v}\left(\times \mathbf{1 0}^{\mathbf{3}} \mathbf{L} \cdot \mathbf{m o l}^{-\mathbf{1}}\right)$ at $\mathbf{2 9 3} \mathbf{~ n m}$ \\
\hline 298 & 10.2 & 9.7 \\
308 & 9.5 & 11.0 \\
\hline
\end{tabular}


hydrogen bonds, etc.) between quencher and fluorescence active molecule [10]. The thermodynamic parameters were calculated in order to elucidate the interaction between the drug and BSA, which can be determined from the Van't Hoff equation:

$$
\ln \mathrm{Ka}=-(\Delta \mathrm{H} / \mathrm{RT})+(\Delta \mathrm{S} / \mathrm{R})
$$

where, $\Delta S=$ entropy change, $\Delta \mathrm{H}=$ enthalpy change, $\mathrm{R}=$ universal gas constant and $\mathrm{Ka}=$ analogous to the Stern-Volmer quenching constants Ksv at the corresponding temperature [21].

The enthalpy change $(\Delta \mathrm{H})$ and the entropy change $(\Delta \mathrm{S})$ can be determined from the slope and intercept of the fitted curve of lnKsv against $1 / \mathrm{T}$, respectively (Figure 5). The free energy, $\Delta \mathrm{G}$ can be estimated from the following relationship:

$$
\Delta \mathrm{G}=\Delta \mathrm{H}-\mathrm{T} \Delta \mathrm{S}
$$

Table 2 shows that $\Delta \mathrm{S}$ was a positive value, and $\Delta \mathrm{H}$ was a small negative value. The negative value of $\Delta \mathrm{H}$ reveals that the formation of BSA-SC complex was an exothermic reaction. Moreover, the negative sign for $\Delta \mathrm{G}$ indicates the spontaneity of the binding process of SC with BSA. According to the views of Ross and Subramanian [22], the model of interaction between drug and biomolecule can be summarized as follows: 1) the positive $\Delta S$ value is frequently regarded as the evidence for a hydrophobic interaction [23] because the water molecules arranged in an orderly fashion around the drug and protein establish a more random configuration; 2) the negative value of $\Delta \mathrm{H}$ can be obtained whenever there is a possibility of hydrogen bonding [22]. Thus both hydrogen bonding and hydrophobic interactions were present in the SC-BSA binding at $280 \mathrm{~nm}$ at both temperatures.

\subsection{Binding Constant and Binding Points}

When sildenafil citrate binds independently to a set of equivalent sites on BSA, the equilibrium between free and bound sildenafil citrate is given by the following equation [24]

$$
\log \left[\left(\mathrm{F}_{\mathrm{o}}-\mathrm{F}\right) / \mathrm{F}\right]=\log \mathrm{K}+\mathrm{nlog}[\mathrm{Q}]
$$

where, $\mathrm{K}$ = binding constant to site of albumin, $\mathrm{n}$ = number of binding sites for drug per albumin.

The values of $K$ and $n$ are calculated from the values of intercept and slope of the plot of $\log \left[\left(F_{o}-F\right) / F\right]$ versus $\log [\mathrm{Q}]$.

Table 3 contains the values of binding constant (K) and binding number (n), at two excitation wavelength of BSA (280 nm and $293 \mathrm{~nm}$ ) which were obtained from the intercept and slope of Figure 6. It was observed that

Table 2. Thermodynamic parameters for BSA-SC system at $280 \mathrm{~nm}$ at two different temperatures (298 K and $308 \mathrm{~K}$ ).

\begin{tabular}{cccc}
\hline $\mathbf{T}(\mathbf{K})$ & $\Delta \mathbf{H}(\mathbf{K J} / \mathbf{m o l})$ & $\Delta \mathbf{S}(\mathbf{J} / \mathbf{m o l})$ & $\Delta \mathbf{G}(\mathbf{K J} / \mathbf{m o l})$ \\
298 & -5.89 & 57.01 & -22.87 \\
308 & & & -23.44 \\
\hline
\end{tabular}

\begin{tabular}{|c|c|c|c|c|}
\hline $\mathbf{T}(\mathbf{K})$ & $\mathrm{K}\left(\times 10^{3} \mathrm{~mol} \cdot \mathrm{L}^{-1}\right)$ at $280 \mathrm{~nm}$ & $\mathbf{n}$ & $\mathrm{K}\left(\times 10^{3} \mathrm{~mol} \cdot \mathrm{L}^{-1}\right)$ at $293 \mathrm{~nm}$ & $\mathbf{n}$ \\
\hline 298 & 14.32 & \multirow{2}{*}{0.9411} & 6.22 & \multirow{2}{*}{1.064} \\
\hline 308 & 12.37 & & 5.62 & \\
\hline
\end{tabular}

Table 3. Binding constant and binding points for BSA-SC system at two excitation wavelength of BSA at two different temperatures.

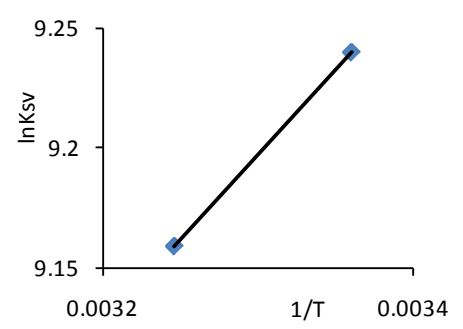

Figure 5. The Van't Hoff plot for BSA-SC system at 280 $\mathrm{nm}$ at two different temperatures (298 K and $308 \mathrm{~K})$. 


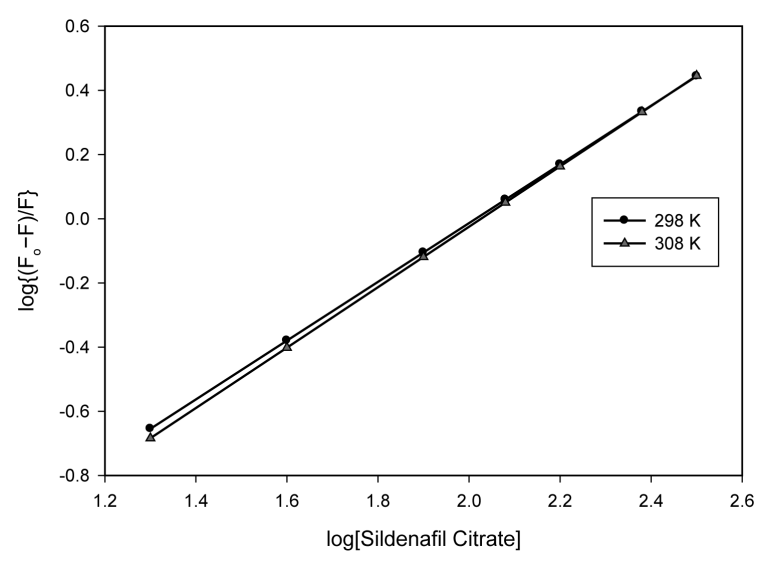

(a)

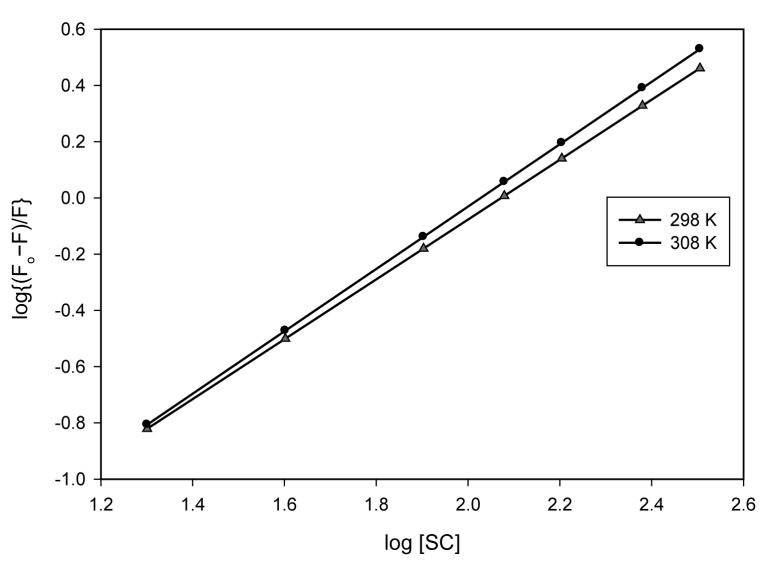

(b)

Figure 6. Plot for binding constant and binding points for BSA-SC system (a) at $280 \mathrm{~nm}$ (b) $293 \mathrm{~nm}$ at two different temperatures.

the binding constant decreases with the increase in temperature of the BSA-SC complex resulting in the reduction of stability of the complex. The values of $n$ were found to be $\approx 1$ at both excitation wavelength of BSA at two different temperatures. The molar ratio of the BSA-SC system at $280 \mathrm{~nm}$ and $293 \mathrm{~nm}$ was 1:1 indicated that one mole SC bound with 1 mole of BSA.

\section{Conclusion}

Drug-drug or drug-protein interactions produce an increase or a decrease in the therapeutic action, or produce various adverse effects that are not normally associated with the drugs [25]-[27]. Interaction of BSA with SC was successfully investigated by fluorescence spectroscopy. Experimental result showed both tryptophan and tyrosine residues of BSA participated in the interactions with SC [27]. The quenching mechanism of fluorescence of BSA by SC was both static and dynamic quenching process results of BSA-SC complex formation. The study of thermodynamic parameters showed that interactions between drugs and BSA were hydrophobic and hydrogen bonding. The stability of BSA-SC complex was decreased with increasing temperatures and it was found that sildenafil citrate bound with BSA with a mole ratio of 1:1.

\section{References}

[1] Boolell, M., Allen, M.J., Ballard, S.A., Gepi-Attee, S., Muirhead, G.J., Naylor, A.M., Osterloh, I.H. and Gingell, C. (1996) Sildenafil: An Orally Active Type 5 Cyclic GMP-Specific Phosphodiesterase Inhibitor for the Treatment of Penile Erectile Dysfunction. International Journal of Impotence Research, 8, 47-52.

[2] Tian, J.N., Liu, J.Q., He, W.Y., Hu, Z.O., Yao, X.J. and Chen, X.G. (2004) Probing the Binding of Scutellarin to Human Serum Albumin by Circular Dichroism, Fluorescence Spectroscopy, FTIR and Molecular Modeling Method. Biomacromolecules, 5, 1956-1961. http://dx.doi.org/10.1021/bm049668m

[3] Malonga, H., Neault, J.F. and Tajmir-Riahi, H.A. (2006) Transfer RNA Binding to Human Serum Albumin: A Model for Protein-RNA Interaction. DNA Cell Biology, 25, 393-398. http://dx.doi.org/10.1089/dna.2006.25.393

[4] Ahmad, B., Parveen, S. and Khan, R.H. (2006) Effect of Albumin Conformation on the Binding of Ciprofloxacinto Human Serum Albumin: A Novel Approach Directly Assigning Binding Site. Biomacromolecules, 7, 1350-1356. http://dx.doi.org/10.1021/bm050996b

[5] Mallick, A., Haldar, B. and Chattopadhyay, N. (2005) Spectroscopic Investigation on the Interaction of ICT Probe 3-Acetyl-4-oxo-6,7-dihydro-12H Indolo-[2,3-a] Quinolizine with Serum Albumins. Journal of Physical Chemistry B, 109, 14683-14690. http://dx.doi.org/10.1021/jp051367z

[6] Carter, D. and Ho, J.X. (1994) Structure of Serum Albumin. Advances in Protein Chemistry, 45, 153-203. http://dx.doi.org/10.1016/S0065-3233(08)60640-3

[7] Lakowicz, J.R. (1999) Principles of Fluorescence Spectroscopy. 2nd Edition, Plenum Press, New York. http://dx.doi.org/10.1007/978-1-4757-3061-6

[8] Peters Jr., T. (1985) Serum Albumin. Advances in Protein Chemistry, 37, 161-245. 
http://dx.doi.org/10.1016/S0065-3233(08)60065-0

[9] Moriyama, Y., Ohta, D., Hachiya, K., Mitsui, Y. and Takeda, K. (1996) Fluorescence Behavior of Tryptophan Residues of Bovine and Human Serum Albumins in Ionic Surfactant Solutions: A Comparative Study of the Two and One Tryptophan(s) of Bovine and Human Albumins. Journal of Protein Chemistry, 15, 265-272.

http://dx.doi.org/10.1007/BF01887115

[10] Papadopoulou, A., Green, R.J. and Franzier, R.A. (2005) Interaction of Flavonoids with Bovine Serum Albumin: A Fluorescence Quenching Study. Journal of Agricultural and Food Chemistry, 53, 158-163. http://dx.doi.org/10.1021/jf048693g

[11] Zhang, J., Yin, Z., Wu, W., Wang, Z., He, R. and Wu, Z. (2012) Characterization of Interaction between Raltitrexed and Bovine Serum Albumin by Optical Spectroscopic Techniques. Chemical Research in Chinese Universities, 28, 963970.

[12] Mostafa, S., EL-Sadek, M. and Alla, E.A. (2002) Spectrophotometric Determination of Ciprofloxacin, Enrofloxacin and Pefloxacin through Charge Transfer Complex Formation. Journal of Pharmaceutical and Biomedical Analysis, 27, 133-142. http://dx.doi.org/10.1016/S0731-7085(01)00524-6

[13] Ni, Y., Liu, G.L. and Kokot, S. (2011) Competitive Binding of Small Molecules with Biopolymers: A Fluorescence Spectroscopy and Chemometrics Study of the Interaction of Aspirin and Ibuprofen with BSA. Analyst, 136, 4794-4801. http://dx.doi.org/10.1039/c1an15550d

[14] Gentili, P.L., Ortica, F. and Favaro, G. (2008) Static and Dynamic Interaction of a Naturally Occurring Photochromic Molecule with Bovine Serum Albumin Studied by UV-Visible Absorption and Fluorescence Spectroscopy. Journal of Physical Chemistry B, 112, 16793-16801. http://dx.doi.org/10.1021/jp805922g

[15] Kwon, S. and Carson, J.H. (1998) Fluorescence Quenching and Dequenching Analysis of RNA Interactions in Vitro and in Vivo. Analytical Biochemistry, 264, 133-140. http://dx.doi.org/10.1006/abio.1998.2846

[16] Steinhardt, J., Krijn, J. and Leidy, J.G. (1971) Differences between Bovine and Human Serum Albumins: Binding Isotherms, Optical Rotatory Dispersion, Viscosity, Hydrogen Ion Titration, and Fluorescence Effects. Biochemistry, 10, 4005-4015. http://dx.doi.org/10.1021/bi00798a001

[17] Bhattacharyya, M., Chaudhuri, U. and Poddar, R.K. (1990) Evidence for Cooperative Binding of Chlorpromazine with Hemoglobin: Equilibrium Dialysis, Fluorescence Quenching and Oxygen Release Study. Biochemical and Biophysical Research Communications, 167, 1146-1153. http://dx.doi.org/10.1016/0006-291X(90)90643-2

[18] Rasoulzadeh, F., Asgari, D., Naseri, A. and Rashidi, M.R. (2010) Spectroscopic Studies on the Interaction between Erlotinib Hydrochloride and Bovine Serum Albumin. DARU Journal of Pharmaceutical Sciences, 18, 179-184.

[19] Kaushelendra, M., Himesh, S., Govind, N., Sita, S.P. and Singhai, A.K. (2011) Method Development and Validation of Metformin Hydrochloride in Tablet Dosage Form. E-Journal of Chemistry, 8, 1309-1313.

[20] Kandagal, P.B., Seetharamappa, J., Shaikh, S.M.T. and Manjunatha, D.H. (2007) Binding of Trazodone Hydrochloride with Human Serum Albumin: A Spectroscopic Study. Journal of Photochemistry and Photobiology A: Chemistry, 185, 239-244. http://dx.doi.org/10.1016/j.jphotochem.2006.06.015

[21] Sun, S-F., Zhou, B., Hou, H-N., Liu, Y. and Xiang, G-Y. (2006) Studies on the Interaction between Oxaprozin-E and Bovine Serum Albumin by Spectroscopic Methods. International Journal of Biological Macromolecules, 39, 197-200. http://dx.doi.org/10.1016/j.ijbiomac.2006.03.020

[22] Ross, P.D. and Subramanian, S. (1981) Thermodynamics of Protein Association Reactions: Forces Contributing to Stability. Biochemistry, 20, 3096-3102. http://dx.doi.org/10.1021/bi00514a017

[23] Li, D., Zhu, J., Jin, J. and Yao, X. (2007) Studies on the Binding of Nevadensin to Human Serum Albumin by Molecular Spectroscopy and Modeling. Journal of Molecular Structure, 846, 34-41. http://dx.doi.org/10.1016/j.molstruc.2007.01.020

[24] Sultana, S., Bin Sayeed, M.S., Ahamed, M.U., Islam, M.S., Bahar, A., Sultan, M.Z. and Hasnat, A. (2013) Interaction of Nalbuphine Hydrochloride with Deoxyribonucleic Acid Measured by Fluorescence Quenching. Drug Research, 63, 224-227. http://dx.doi.org/10.1055/s-0033-1334874

[25] Rahman, M.A., Salam, M.A., Sultan, M.Z., Hossain, K., Rahman, A. and Rashid, M.A. (2014) DSC and HPLC Studies of Some Common Antidiabetic and Antihypertensive Drugs. Bangladesh Pharmaceutical Journal, 17, 123-127.

[26] Ahsan, M.R., Sultan, M.Z., Amjad, F.M., Sultana, S., Baki, M.A., Hossain, M.A., Hossain, M.A. and Amran, M.S. (2012) The Study of in Vitro Interaction of Ciprofloxacin with Paracetamol and Zinc in Aqueous Medium. Journal of Scientific Research, 4, 701-708. http://dx.doi.org/10.3329/jsr.v4i3.8709

[27] Rokonujjaman, M., Salam, M.A. and Sultan, M.Z. (2015) In Vitro Study of Interactions of Sildenafil Citrate with Bovine Serum Albumin in Presence of Bisoprolol Fumarate and Metformin Hydrochloride by Fluorescence Spectrophotometry. British Journal of Medicine \& Medical Research, 5, 362-375. http://dx.doi.org/10.9734/BJMMR/2015/11655 
Scientific Research Publishing (SCIRP) is one of the largest Open Access journal publishers. It is currently publishing more than 200 open access, online, peer-reviewed journals covering a wide range of academic disciplines. SCIRP serves the worldwide academic communities and contributes to the progress and application of science with its publication.

Other selected journals from SCIRP are listed as below. Submit your manuscript to us via either submit@scirp.org or Online Submission Portal.
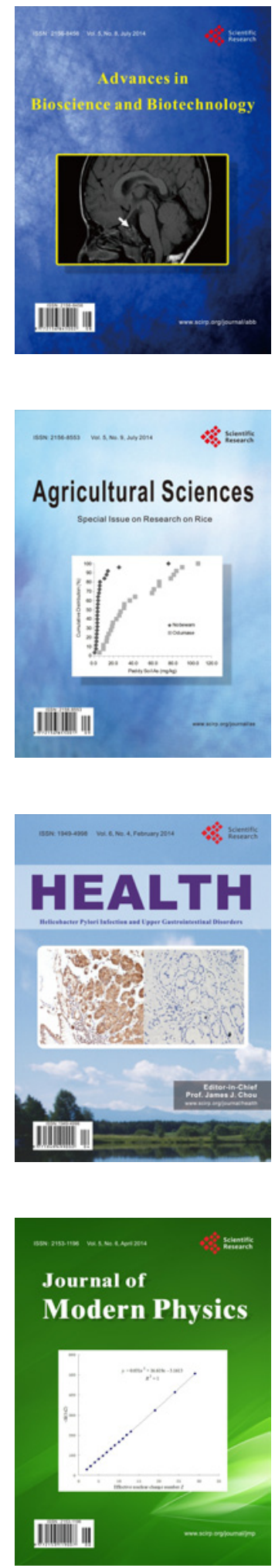
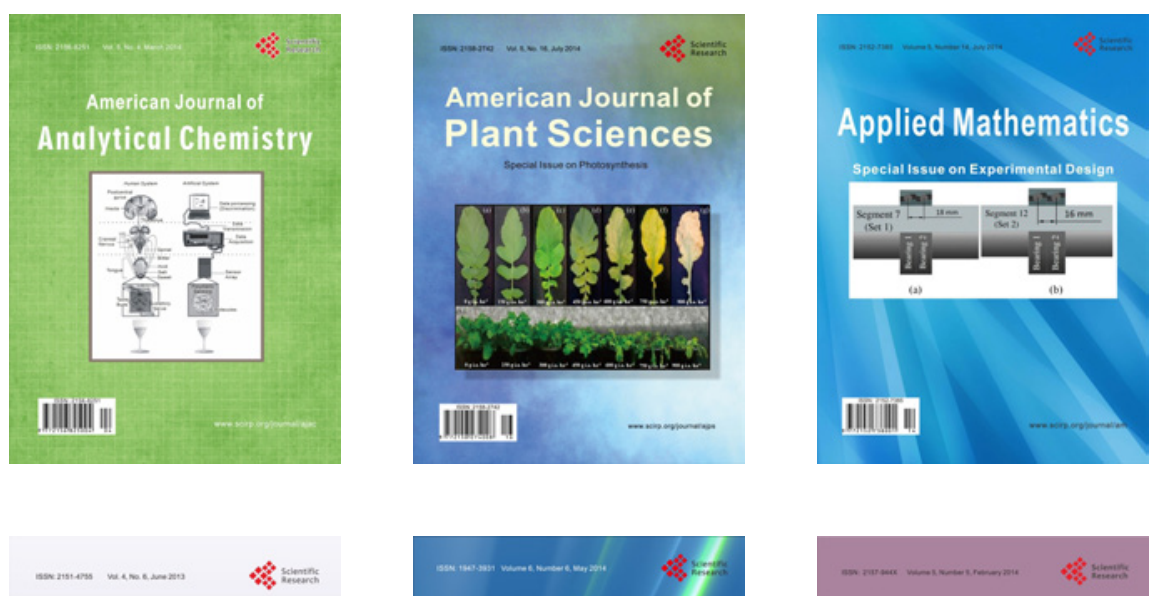

Creative Education
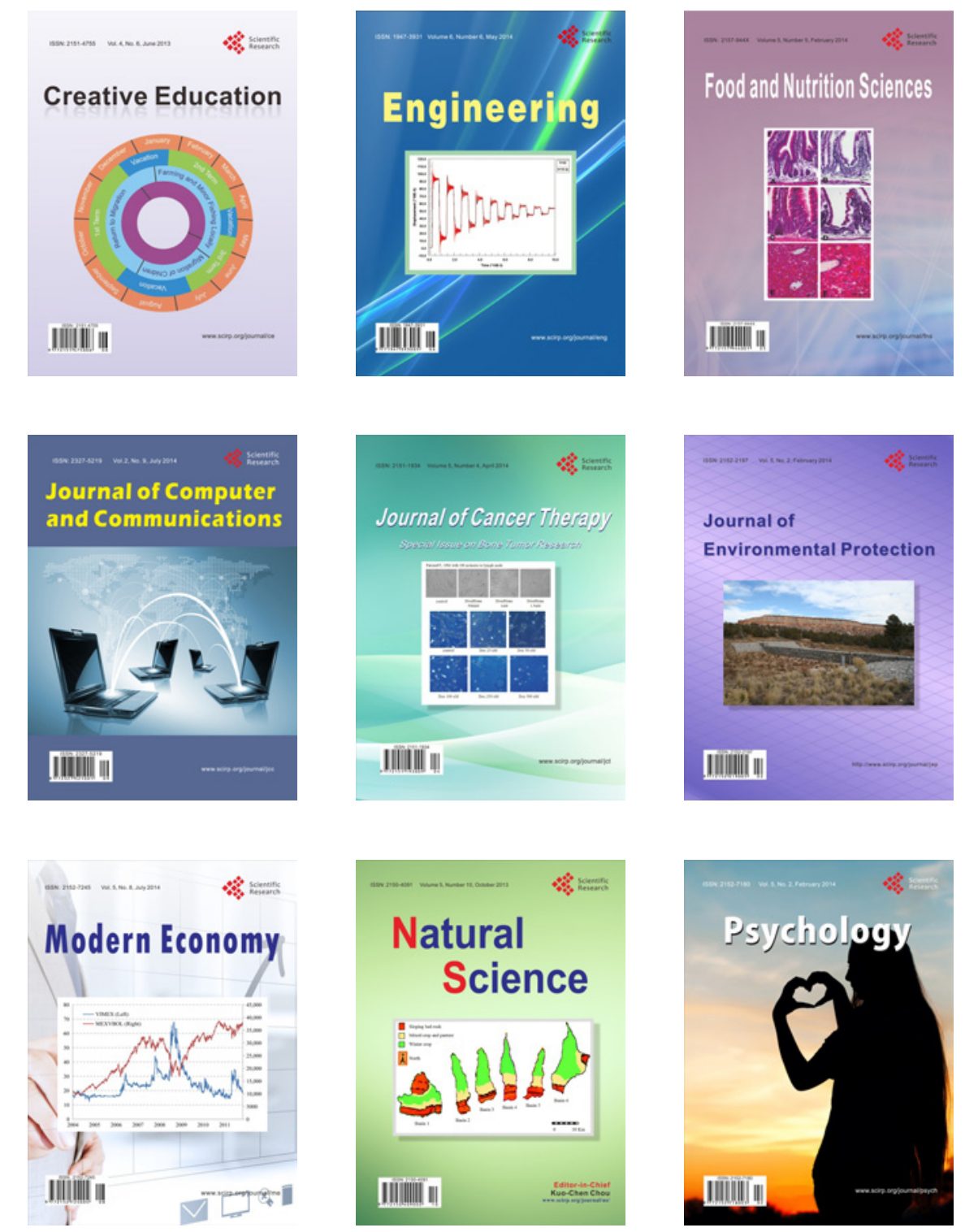